\title{
PREPARATION OF PVP HYDROGEL NANOPARTICLES USING LECITHIN VESICLES
}

\author{
Vânia Blasques Bueno e Luiz Henrique Catalani* \\ Departamento de Química Fundamental, Instituto de Química, Universidade de São Paulo, CP 26077, 05513-970 São Paulo - SP, Brasil \\ Katia Regina Perez Daghastanli, Iolanda Midea Cuccovia e Hernan Chaimovich \\ Departamento de Bioquímica, Instituto de Química, Universidade de São Paulo, CP 26077, 05513-970 São Paulo - SP, Brasil
}

Recebido em 21/6/10; aceito em 20/8/10; publicado na web em 15/10/10

\begin{abstract}
Hydrogels micro, sub-micro and nanoparticles are of great interest for drug encapsulation and delivery or as embolotherapic agents. In this work it is described the preparation of nano and sub-microparticles of pre-formed, high molecular weight and monomer free $\operatorname{poly}(N$-vinyl-2-pyrrolidone) encapsulated inside the core of lecithin vesicles. The hydrogel particles are formed with a very narrow diameter distribution, of about $800 \mathrm{~nm}$, and a moderate swelling ratio, of approximately 10.
\end{abstract}

Keywords: PVP hydrogel nanoparticle; lecithin vesicle; photo-Fenton reaction.

\section{INTRODUCTION}

Hydrogel nanoparticles (nanogels) are of interest due to their ability to combine the advantages of biocompatibility, inherent to most hydrogels, ${ }^{1}$ and small size. ${ }^{2}$ Potential applications of nanogels include controlled drug delivery systems ${ }^{3}$ (oral ${ }^{4}$ and/or parenteral ${ }^{5}$ delivery) and alternative therapies, like embolotherapy. ${ }^{6}$

Nanogels can be obtained from monomer polymerization in presence of difunctional monomers, either in w/o emulsions ${ }^{7,8}$ or using the core of reverse micelles as formatting system. ${ }^{9}$ Alternatively, nanogels can be prepared by inclusion in reverse micelles of pre-formed polymers, followed by crosslinking. ${ }^{10}$ Vesicles also can be used to obtain hydrogels nanoparticles, by monomer encapsulation followed by polymerization ${ }^{11}$ or gelation of encapsulated polymers, generally induced by sol-gel temperature transitions ${ }^{12}$ or ionic crosslinking, ${ }^{13}$ typically without removal of the lipid bilayer. ${ }^{14}$ These gel-like vesicles work as cell models, since they have elastic modulus comparable to that of cell cytoplasm ${ }^{14}$ and are considered artificial cytoskeletons. ${ }^{14,15}$ Vesicles containing poly $(N$ isopropylacrylamide) are good examples. This polymer responds to temperature changes forming physical gels on a reversible process, even within vesicles. ${ }^{16}$ This temperature induced sol-gel transition within the vesicle mimics cell stiffening. ${ }^{12}$ Hydrogel-liposome assemblies (lipobeads) can also be used as drug delivery systems. ${ }^{17}$ The lipid bilayer is often left intact and the encapsulated polymer is not crosslinking.

Vesicles have advantages compared to other systems for producing nanogels, since these assemblies permit more diameter control alternatives. ${ }^{18}$ The particle diameter can be controlled varying the vesicles diameter from a few nanometers to millimeters and can be obtained with a narrow size distribution. Vesicles can be prepared using low amounts of non-toxic solvents and this compares favorably with other methods such as emulsion polymerization. The major component of a vesicle preparation is water and a non-toxic surfactant can be chosen, thereby resulting in a biocompatible preparation.

Poly( $N$-vinyl-2-pyrrolidone) hydrogels can be prepared by several straightforward methodologies. ${ }^{19-22}$ One of these methods involves the use of photo-Fenton reaction ${ }^{21}$, using ferric ions, hydrogen peroxide and UVA radiation. ${ }^{22}$

Here we describe the use of lecithin vesicles as formatting system to obtain poly( $N$-vinyl-2-pyrrolidone) hydrogel particles, using photo-Fenton or Fenton reactions for crosslinking.

*e-mail: catalani@usp.br

"This paper is dedicated to Prof. Hans Viertler

\section{EXPERIMENTAL}

\section{Materials}

Egg phosphatidylcholine was purified from egg yolks as described by Maximiano et al... ${ }^{23}$ Soy lecithin was obtained from crude soy lecithin capsules by purification with the same method used for egg phosphatidilcholine. ${ }^{23}$ Dioctadecyldimethylammonium chloride (DODAC) was obtained from the bromide salt (DODAB; Aldrich) after ion exchange with a Dowex-21K resin (Fluka) in the chloride form in methanol. 1,2-Dipalmitoyl-3trimethylammonium-propane chloride (DPTMA) was synthesized as described previously ${ }^{24}$ as bromide salt, which was exchanged for chloride as indicated for DODAC. Poly ( $N$-vinyl-2-pyrrolidone) (PVP) (Plasdone K90, $\left.\bar{M}_{w}=1,300,000\right)$ was kindly donated by BASF. $\mathrm{FeCl}_{2}, \mathrm{FeCl}_{3}$ and $\mathrm{H}_{2} \mathrm{O}_{2} 30 \%$ (Aldrich), $\mathrm{NaCl}$ (Merck) and $\mathrm{CH}_{2} \mathrm{Cl}_{2}$ (Synth Brazil) were analytical grade and used as received. Water was deionized.

\section{Methods}

\section{PVP encapsulation in liposome}

PVP containing vesicles were obtained as follows (Figure 1): $0.5 \mathrm{~mL}$ of a $\mathrm{CH}_{2} \mathrm{Cl}_{2}$ solution containing $50 \mathrm{mg}$ of egg or soy phosphatidylcholine $\left(100 \mathrm{mg} \mathrm{mL}^{-1}\right)$ were injected into $5 \mathrm{~mL}$ of PVP aqueous solution $\left(80 \mathrm{~g} \mathrm{~L}^{-1}\right)$, containing $17 \mathrm{mmol} \mathrm{L}^{-1} \mathrm{FeCl}_{2}$ maintained at $50{ }^{\circ} \mathrm{C}$. $\mathrm{CH}_{2} \mathrm{Cl}_{2}$ solution was injected with a syringe adapted in a KD Scientific Inc. Model KDS120 Push-Pull Pump, equipped with a fine-gauge needle (No 3D). During injection, a $\mathrm{N}_{2}$ stream was bubbled into PVP solution, which continued after liposome formation until removal of residual solvent. Liposome suspension was centrifuged at $22,800 \times \mathrm{g}$ for $30 \mathrm{~min}$ (Hitachi Himac CR20B2 centrifuge; Hitachi Ltd.) at $25{ }^{\circ} \mathrm{C}$ to remove non-entrapped polymer from the external phase. The liposomecontaining pellet was washed twice by centrifugation under same conditions in saline solution $\left(51 \mathrm{mmol} \mathrm{L}^{-1}\right)$. The washed pellet was suspended on $20 \mathrm{~mL}$ of $\mathrm{NaCl}_{(\mathrm{aq})}$.

PVP concentration inside vesicles was estimated using Lugol method. ${ }^{25}$ Resulting PVP complex with Lugol Reagent (PVP-I ${ }_{3}^{-}$) absorbs at $400 \mathrm{~nm}$, and the PVP concentration was obtained using appropriate calibration curve. The encapsulation yield (EY) was calculated using Equation 1. 

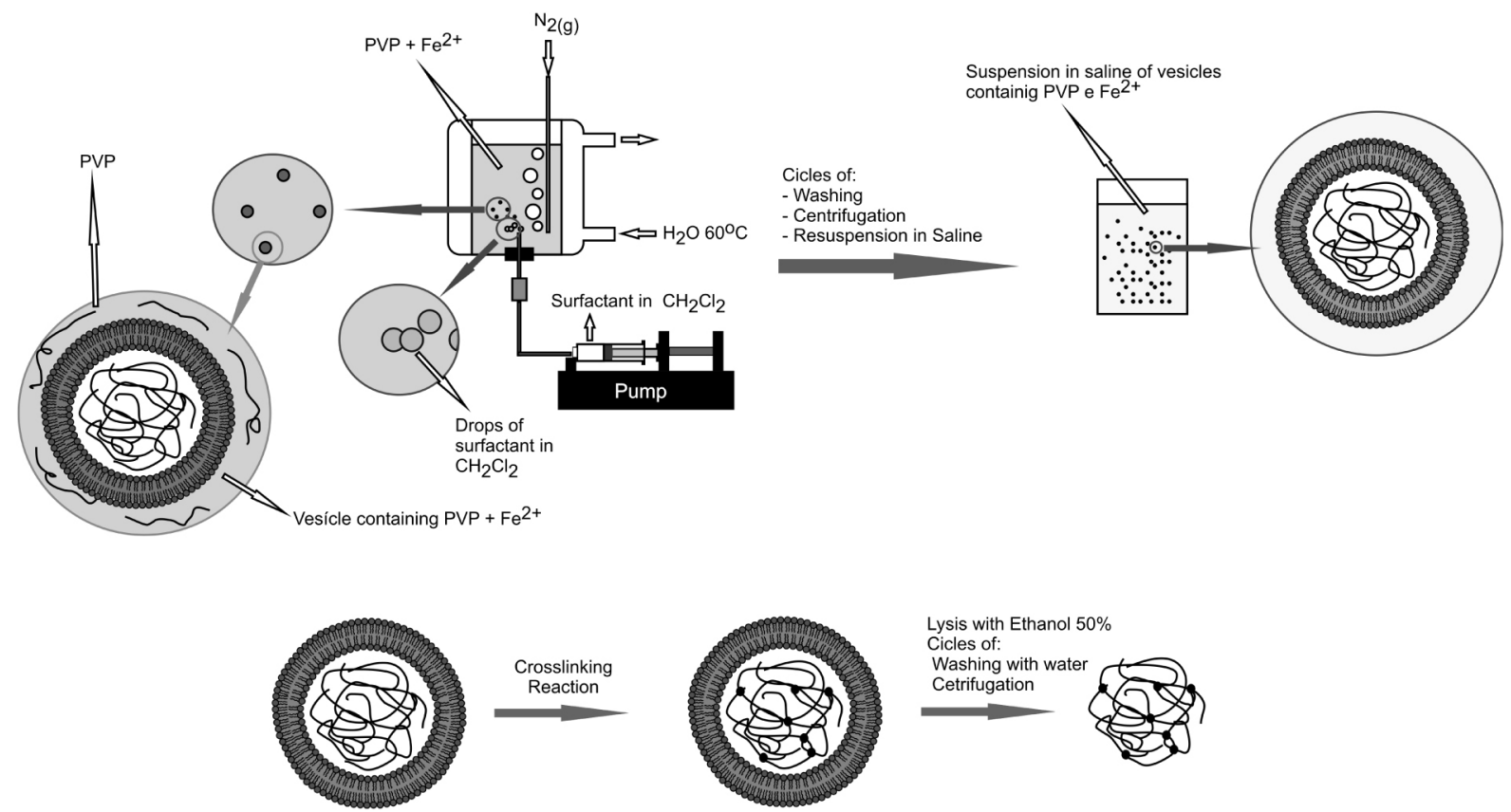

Figure 1. Production of PVP hydrogel particles

$$
E Y(\%)=\frac{m_{P V P}^{\text {vesicles }}}{0.4} \times 100
$$

where $m_{P V P}^{\text {vesicles }}$ is the mass of encapsulated PVP in the vesicles pellet and 0.4 is the mass of PVP in the initial solution (in $\mathrm{g}$ ).

\section{PVP entrapped polymerization}

To crosslink PVP inside the vesicles, $4 \mathrm{~mL}$ of $\mathrm{H}_{2} \mathrm{O}_{2}$ diluted on $\mathrm{NaCl}_{\text {(aq) }}\left(51 \mathrm{mmol} \mathrm{L}^{-1}\right)$ was added to the PVP-containing vesicles $\left(\left[\mathrm{H}_{2} \mathrm{O}_{2}\right]_{\text {final }}=200 \mathrm{mmol} \mathrm{L}^{-1}\right) .{ }^{22} \mathrm{As} \mathrm{Fe}^{2+}$ can be oxidized to $\mathrm{Fe}^{3+}$ inside vesicles before $\mathrm{H}_{2} \mathrm{O}_{2}$ addition, to promote crosslinking by photoFenton reaction ${ }^{21} \mathrm{H}_{2} \mathrm{O}_{2}$ containing vesicles suspension was submitted to $12 \mathrm{~h}$ of UV radiation $(360 \mathrm{~nm})$. The hydrogel particles were purified by lysing vesicles washing $3 \times$ with ethanol $50 \%$. The resulting pellet was resuspended in water and freeze-dried.

\section{Dynamic light scattering measurements}

The determination of particles size distribution was carried out by dynamic light scattering (DLS), using a spectrometer from Brookhaven Instruments. The average hydrodynamic diameters were obtained from the unimodal distribution of particles analyzed by Zeta PALS Particle Sizing Software Version 2.29.

\section{Scanning electron microscopy (SEM)}

Particles were analyzed by SEM (FEG-SEM, model FEG 7401F, from Jeol). Samples were prepared by fixing the particles (freezedried powder) on a double-face copper tape and the specimens were analyzed without coating.

\section{Swelling ratio determination $(Q)$}

Swelling ratio $(Q)$ determination was done by weighing the swollen particles pellet in an analytical balance $\left(\mathrm{m}_{\mathrm{swo}}\right)$, followed by freeze drying and weighing the dry pellet $\left(\mathrm{m}_{\text {dry }}\right)$. $Q$ was calculated directly by Equation 2 .

$$
Q=\frac{\left(\mathrm{m}_{\mathrm{swo}}-\mathrm{m}_{\mathrm{dry}}\right)}{\mathrm{m}_{\mathrm{dry}}}
$$

\section{RESULTS AND DISCUSSION}

\section{Polymer encapsulation}

The efficiency of vesicle encapsulation depends on polymer size and decreases with the increase of polymer molecular weight. ${ }^{26,27}$ Szoka and Papahadjopoulos ${ }^{28}$ found that encapsulation efficiency decreases with the increase of molecular weight of the encapsulated protein. Dominak et al. ${ }^{26}$ observed the same inverse relationship between encapsulation efficiency and molecular weight studying polyethylene glycol and dextran encapsulation in giant vesicles. To encapsulate PVP, various surfactants were tested, including lecithin from egg yolk and soybeans and cationic surfactants. Table 1 shows the surfactants and their respective PVP encapsulation yield. As each vesicle in solution can have different encapsulation values, ${ }^{26}$ it is important to emphasize that PVP inclusion was measured by estimating the total amount that was incorporated and therefore the incorporation represents an average over all vesicles.

Table 1. PVP encapsulation in obtained vesicles

\begin{tabular}{lc}
\hline Surfactant & EY $(\%)$ \\
\hline Egg lecithin & $0.8 \pm 0.1$ \\
Soy lecithin & $2.0 \pm 0.3$ \\
DPPC & $0.6 \pm 0.1$ \\
DODAC 1\% + soy lecithin & $0.4 \pm 0.1$ \\
DPTMA 1\% + soy lecithin & $2.0 \pm 0.4$ \\
\hline
\end{tabular}

The best encapsulation efficiency was obtained with soy lecithin vesicles. Lecithins of different sources exhibit distinct properties. ${ }^{23,29}$ In particular the length of the apolar portion of the molecule and the insaturation of the alkyl chain will result in vesicles with different properties. ${ }^{30}$ The method used to obtain vesicle encapsulated PVP also contributes to high encapsulation efficiency. ${ }^{18}$

Since the method used to crosslink the encapsulated polymer requires long irradiation times (photo-Fenton reaction), the addition 
of cationic surfactants decreases vesicle aggregation during irradiation by increasing vesicle repulsion. Two saturated surfactants where tested: DODAC and DPTMA. Encapsulation efficiency was higher with DPTMA than with DOCAC. DODAC contains two octadecyl chains linked to the tetraalkylammonium group; in DPTMA the acyl chains are attached to a propanediol moiety linked to tetraalkylammonium group (Figure 2). Bilayer packing defects are expected ${ }^{31,32}$ upon incorporation of DODAC to lecithin causing a decrease in polymer entrapment. Measurements of polymer leak showed that entrapped PVP was retained after several washes (supernatant PVP concentration was measured as $<10^{-4} \mathrm{~g} \mathrm{~L}^{-1}$ for DPPC vesicles and as $0.02 \mathrm{~g} \mathrm{~L}^{-1}$ for DODAC/lecithin vesicles, after 5 wash cycles).

(A)<smiles>CCCCCCCCCCCCCCCC(=O)OCC(C[N+](C)(C)C)OC(=O)CCCCCCCCCCCCCCC</smiles>

(B)

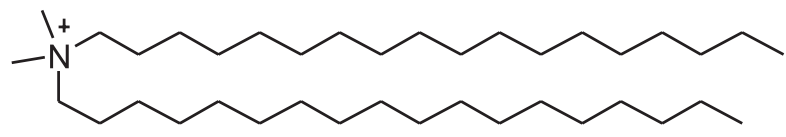

Figure 2. Structures of (A) DPTMA and (B) DODAC

\section{Crosslinking reaction}

Two methods were used to crosslink the polymer. The Fenton reaction, an efficient method to obtain PVP hydrogels with good mechanical properties, ${ }^{22}$ has been used to obtain PVP nanogels with superabsorbent properties. ${ }^{10}$ Photo-Fenton reaction, a photochemical analog of Fenton reaction, also produces PVP hydrogels ${ }^{21}$ (Scheme 1).

$$
\begin{gathered}
\mathrm{Fe}^{2+}+\mathrm{H}_{2} \mathrm{O}_{2} \rightarrow \mathrm{Fe}^{3+}+\mathrm{OH}^{\bullet}+\mathrm{OH}^{-} \\
\mathrm{Fe}^{3+}+\mathrm{HO}^{-} \rightarrow \mathrm{FeOH}^{2+} \\
\mathrm{FeOH}^{2+}+\mathrm{H}_{2} \mathrm{O}_{2} \stackrel{h v}{\longrightarrow} \mathrm{Fe}^{2+}+\mathrm{OH}^{\bullet}
\end{gathered}
$$

Scheme 1. Hydroxyl radical generation from Fenton and photo-Fenton reactions

The Fenton reaction is interesting because it allows a fast route to obtain PVP hydrogels with any desired format. ${ }^{33}$ However, this reaction requires $\mathrm{Fe}^{2+}$ which autoxidizes. On the other hand, photo-Fenton reaction uses $\mathrm{Fe}^{3+}$ ions, $\mathrm{H}_{2} \mathrm{O}_{2}$ and $\mathrm{UV}$ radiation $(\lambda=365 \mathrm{~nm})$. Since the vesicles can scatter and react with $\mathrm{H}_{2} \mathrm{O}_{2}$ (lipoperoxidation), the UV dose and $\mathrm{H}_{2} \mathrm{O}_{2}$ concentrations were higher than those described. ${ }^{21}$

Fenton and photo-Fenton reactions did not change significantly the vesicles diameter distribution (Figures 3 and 4). This finding does not imply that the lipid bilayer remains unchanged during crosslinking reaction, since hydroxyl radical is known to react with unsaturated acyl chains. ${ }^{34}$

\section{Particle characterization}

When conventional Fenton reaction was used no pellet was obtained after vesicle's lysis, evidencing absence of crosslinking, probably due $\mathrm{Fe}^{2+}$ depletion via its autoxidation. A phosphorus-free yellow pellet was obtained after crosslinking by photo-Fenton reac-

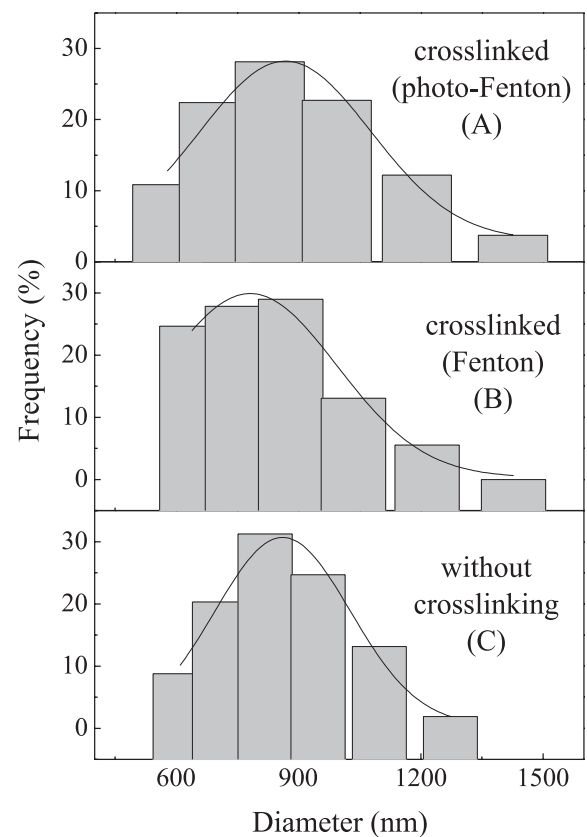

Figure 3. Diameter distribution of egg lecithin vesicles containing PVP. (A) vesicles submitted to Fenton reaction; (B) vesicles submitted to photo-Fenton reaction and $(C)$ vesicles prior to crosslinking reaction

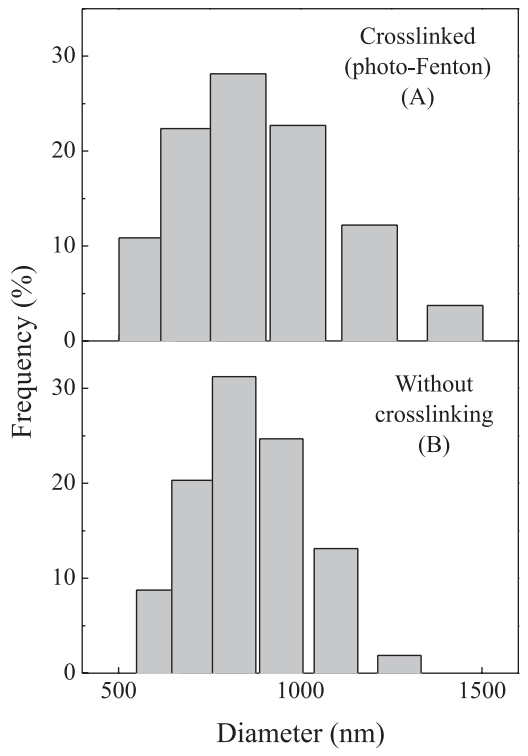

Figure 4. Diameter distribution of soy lecithin vesicles containing PVP. (A) vesicles submitted to photo-Fenton reaction and $(B)$ vesicles prior to crosslinking reaction

tion and vesicles lyses. ${ }^{39}$ This pellet was resuspended in water and analyzed by SEM and DLS. Results demonstrated the presence of a formless particulate material with dimensions comparable to vesicles (Figures 5 and 6).

The diameter of nano and sub-microgel and nanogel particles can be controlled by choosing the vesicle preparation method. Polyacrylamide nanogels (from monomers) covered by phospholipids bilayers obtained by detergent depletion ${ }^{35}$ or freeze-thaw cycles followed by extrusion ${ }^{36} /$ sonication ${ }^{11,17}$ presented diameters of 100 and $200 \mathrm{~nm}$, respectively. Larger nanogels (about $450 \mathrm{~nm}$ ) are obtained from encapsulation of $20 \%$ dextran hydroyethylmethacrylate solution $(\bar{M} n=19000)$ inside vesicles obtained by phospholipids film hydration, followed by extru- 

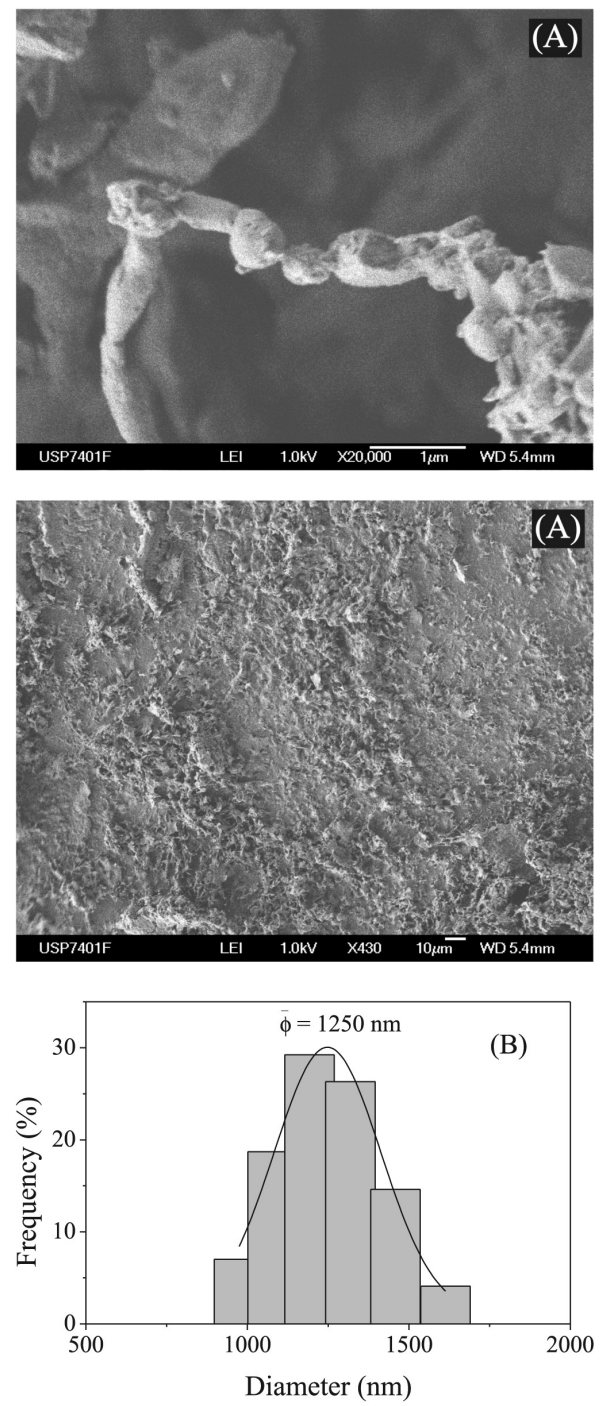

Figure 5. SEM image of freeze-dried particles obtained from egg lecithin vesicles $(A)$ and $D L S$ particles diameter distribution $(B)$

sion. ${ }^{37}$ Poly(ethylenedioxythiophene)/poly(styrenesulfonate) ${ }^{13}$ and poly $(N \text {-isopropylacrylamide })^{12,16}$ microgels, in conjunction with lipid bilayers, are obtained by injecting a polymer solution inside GUVs, followed by freeze-thaw cycles and electroporation. The vesicle diameters, in these latter cases, vary from 5 to $100 \mu \mathrm{m}$.

The hydrogel particles obtained here showed no defined morphology, in spite of being obtained from spherical vesicles. Vesicles may be destabilized during crosslinking by $\mathrm{H}_{2} \mathrm{O}_{2}$ oxidation and ensuing lipoperoxidated ${ }^{38}$ (Figure 7). Fluctuation of crosslinking density, known to influence hydrogel particle morphology, may also account for the lack of defined shape. ${ }^{13}$ Non spherical particles have also been reported with other nanogels prepared using vesicles. ${ }^{17,37}$

Particle swelling was estimated directly and the swelling ratio $(Q)$ was 10 , i.e., particles absorb only 10 times their mass in water. This is a strong indication that the crosslinking density is high since $Q$ is inversely proportional to the ability of absorbing water.

Swelling of nanogels formatted from vesicles has seldom been discussed in literature. In the case of poly $(N$-isopropyl acrylamide) hydrogels and copolymers, coagulation of particles was observed instead of the variation in swelling. Kasakov et al. have extensively studied this systems ${ }^{11,17,36}$ mainly in regard to the interaction between particle and liposome. Since the hydrogel used
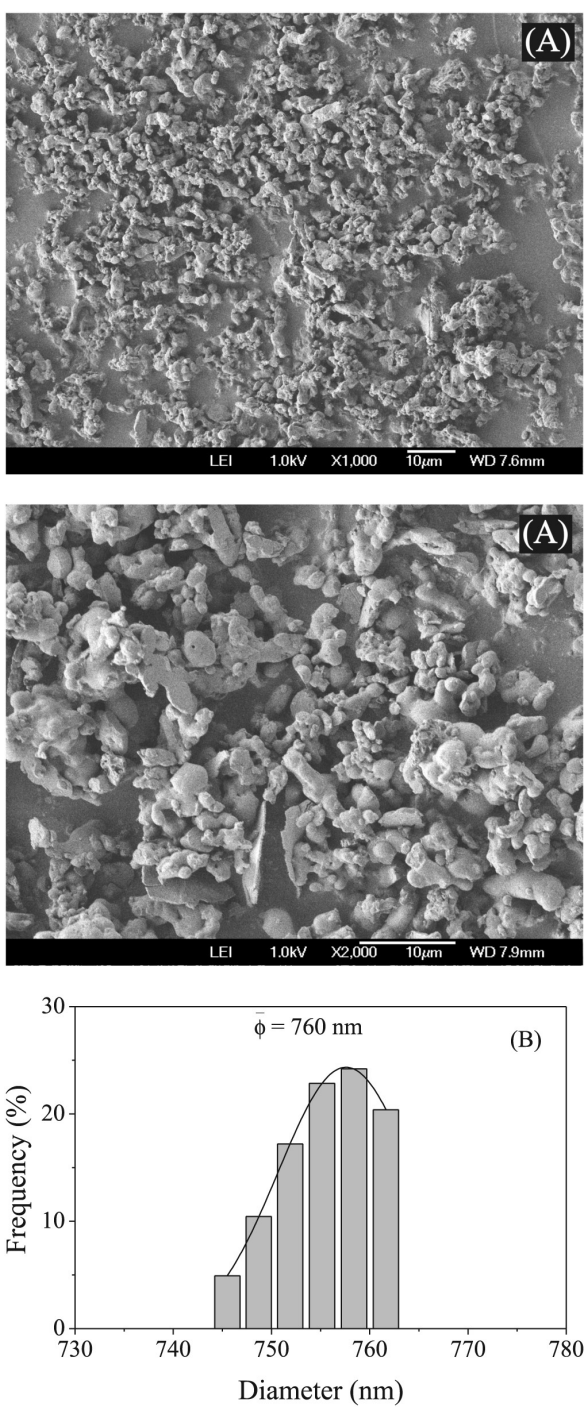

Figure 6. SEM image of freeze-dried particles obtained from soy lecithin vesicles $(A)$ and DLS particles diameter distribution $(B)$

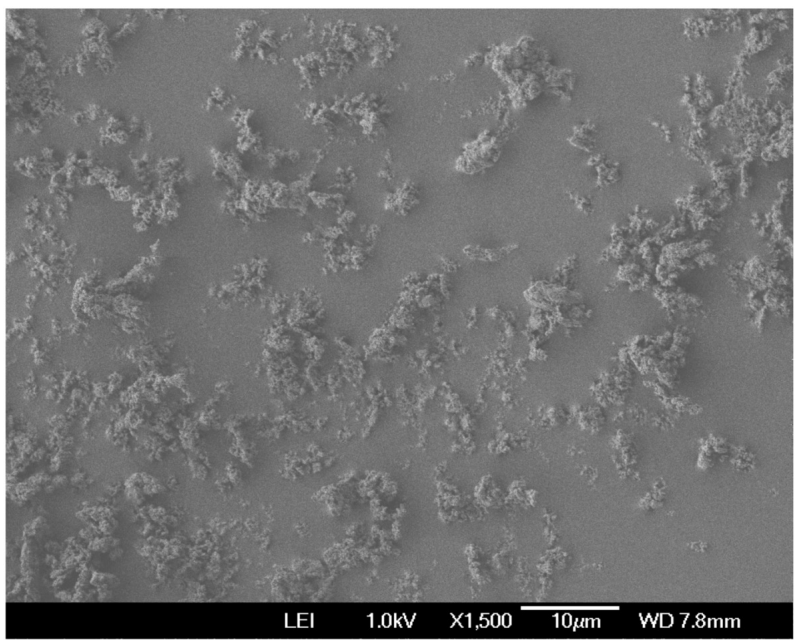

Figure 7. SEM image of particles obtained from soy lecithin vesicles with $10 \%$ DPTMA

is thermo- and pH-responsive, coagulation was observed upon heating, including coagulation of the lipid bilayer, which, after 
cooling, surround the entire set of nanoparticles in a reversible process. ${ }^{36}$ The authors also observed an increase in diameter with $\mathrm{pH}$ change: $100 \mathrm{~nm}$ at $\mathrm{pH} 6.5$ to $300 \mathrm{~nm}$ at $\mathrm{pH} 3.0$, with dimerization of particles. ${ }^{17}$

\section{CONCLUSION}

Injected lecithin vesicles can encapsulate high molecular weight PVP. The encapsulated polymer can be crosslinked by photo-Fenton reaction and hydrogel nano and sub-microparticles can be isolated. Spherical morphology was not achieved, but the produced hydrogel particles have a narrow diameter distribution compatible with the vesicles diameter distribution.

\section{REFERENCES}

1. Rosiak, J. M.; Yoshii, F.; Nucl. Instrum. Methods Phys. Res., Sect. B 1999, 151, 56 .

2. Tao, S. L.; Desai, T. A.; Adv. Drug Delivery Rev. 2003, 55, 315.

3. Mathews, A.; Ha, C.-S.; Cho, W.-J.; Kim, I.; Drug Delivery 2006, 13, 245.

4. Mundargi, R. C.; Patil, S. A.; Kulkarni, P. V.; Mallikarjuna, N. N.; Aminabhavi, T. M.; J. Microencapsulation 2008, 25, 228.

5. Nguyen, K. T.; Shukla, K. P.; Moctezuma, M.; Braden, A. R. C.; Zhou, J.; Hu, Z.; Tang, L.; J. Biomed. Mater. Res., Part A 2009, 88, 1022.

6. Rao, V. R.; Ravimandalam, K.; Jayakrishnan, A.; Thanoo, B. C.; Radhakrishnan, V. V.; Gupta, A. K.; Kumar, S.; Joseph, S.; Unni, M.; Rao, A. S.; J. Neuroradiology 1991, 18, 61.

7. Sahiner, N.; Godbey, W. T.; Mcpherson, G. L.; John, V. T.; Colloid Polym. Sci. 2006, 284, 1121.

8. Imaz, A.; Forcada, J.; Macromol. Symp. 2009, 281, 85.

9. Bharali, D. J.; Sahoo, S. K.; Mozumdar, S.; Maitra, A. J.; J. Colloid Interface Sci. 2003, 258, 415.

10. Bueno, V. B.; Cuccovia, I. M.; Chaimovich, H.; Catalani, L. H.; Colloid Polym. Sci. 2009, 287, 705.

11. Kazakov, S.; Kaholek, M.; Kudasheva, D.; Teraoka, I.; Cowman, M. K.; Levon, K.; Langmuir 2003, 19, 8086.

12. Jesorka, A.; Markstroem, M.; Orwar, O.; Langmuir 2005, 21, 1230.

13. Jesorka, A.; Markstroem, M.; Karlsson, M.; Orwar, O.; J. Phys. Chem. B 2005, 109, 14759 .

14. Kremer, S.; Campillo, C.; Pepin-Donat, B.; Viallat, A.; Brochard-Wyart, F.; EPL 2008, 82, 48002/1.
15. Campillo, C.; Pepin-Donat, B.; Viallat, A.; Soft Matter 2007, 3, 1421.

16. Markstroem, M.; Gunnarsson, A.; Orwar, O.; Jesorka, A.; Soft Matter 2007, 3, 587.

17. Kazakov, S.; Levon, K.; Curr. Pharm. Des. 2006, 12, 4713.

18. Lasic, D. D.; Biochem. J. 1988, 256, 1.

19. Rosiak, J. M.; J. Controlled Release 1994, 31, 9.

20. Kadlubowski, S.; Henke, A.; Ulanski, P.; Rosiak, J. M.; Bromberg, L.; Hatton, T. A.; Polymer 2007, 48, 4974.

21. Fechine, G. J. M.; Barros, J. A. G.; Catalani, L. H.; Polymer 2004, 45, 4705.

22. Barros, J. A. G.; Fechine, G. J. M.; Alcantara, M. R.; Catalani, L. H.; Polymer 2006, 47, 8414.

23. Maximiano, F. A.; da Silva, M. A.; Daghastanli, K. R. P.; de Araujo, P. S.; Chaimovich, H.; Cuccovia, I. M.; Quim. Nova 2008, 31, 910.

24. Moss, R. A.; Gangulu, S.; Okumura, Y.; Fujita, T.; J. Am. Chem. Soc. 1990, 112, 6391.

25. Leger, C.; Nguyen, Q. T.; Neel, J.; Streicher, C.; Macromolecules 1995 , $28,143$.

26. Dominak, L. M.; Keating, C. D.; Langmuir 2007, 23, 7148.

27. Dominak, L. M.; Keating, C. D.; Langmuir 2008, 24, 13565.

28. Szoka, F., Jr.; Papahadjopoulos, D.; Annu. Rev. Biophys. Bioeng. 1980, 9, 467.

29. Palacios, L. E.; Wang, T.; J. Am. Oil Chem. Soc. 2005, 82, 571.

30. Nagarajan, R.; Ruckenstein, E.; J. Colloid Interface Sci. 1979, 71, 580.

31. Kumar, V. V.; Indian J. Biochem. Biophys. 1993, 30, 135.

32. Batenjany, M. M.; Wang, Z.-Q.; Huang, C.-H.; Levin, I. W.; Biochim. Biophys. Acta, Biomembr. 1994, 1192, 205.

33. Catalani, L. H.; Fechine, G. J. M.; Barros, J. A. G.; BR PI 0402081-2 2006. (CA 147:508389)

34. Megli, F. M.; Sabatini, K.; Chem. Phys. Lipids 2003, 125, 161.

35. Schillemans, J. P.; Flesch, F. M.; Hennink, W. E.; van Nostrum, C. F.; Macromolecules 2006, 39, 5885.

36. Kazakov, S.; Kaholek, M.; Teraoka, I.; Levon, K.; Macromolecules 2002, 35, 1911.

37. van Thienen, T. G.; Lucas, B.; Flesch, F. M.; Nostrum, C. F.; Demeester, J.; De Smedt, S. C.; Macromolecules 2005, 38, 8503.

38. Dobretsov, G. E.; Borschevskaya, T. A.; Petrov, V. A.; Vladimirov, Yu. A.; FEBS Lett. 1977, 84, 125.

39. Rouser, G.; Fleischer, S.; Yamamoto, A.; Lipids 1970, 5, 494. 